\title{
Recomendações médicas para a educação da criança-problema: um estudo de manuais de higiene mental, 1939-1947
}

\author{
Doctor's recommendations concerning the \\ education of the problem child: a study of mental hygiene \\ handbooks, 1939-1947
}

\author{
Ana Laura Godinho \\ Lima \\ Professora da Escola de Artes, \\ Ciências e Humanidades/ \\ Universidade de São Paulo. \\ Av. Arlindo Bettio, 1000 \\ 03828-000 - São Paulo - SP - Brasil \\ alglima@usp.br
}

LIMA, Ana Laura Godinho. Recomendações médicas para a educação da criança-problema: um estudo de manuais de higiene mental, 1939-1947. História, Ciências, Saúde - Manguinhos, Rio de Janeiro, v.20, n.1, jan.-mar. 2013, p.317-325.

\section{Resumo}

Apresenta os primeiros resultados de uma investigação a respeito das orientações para a educação da criança-problema contidas em compêndios de higiene infantil redigidos por médicos brasileiros. Destinadas às mães e professoras encarregadas da educação das crianças, essas obras procuravam explicar a origem dos problemas de comportamento mais comuns e ofereciam instruções para a superação dessas dificuldades que prejudicavam o desenvolvimento e o ajustamento da criança à família e à escola. A análise preliminar de dois manuais, à luz do referencial teórico de Foucault e outros autores sobre a governamentalidade, indica que os compêndios examinados procuravam, acima de tudo, orientar os adultos a fazer um bom uso do poder na relação com as crianças.

Palavras-chave: manuais de higiene; puericultura; história da criança e da família; criança-problema; governamentalidade.

\section{Abstract \\ The article presents the initial findings of a study on guidelines for the education of the problem child, as found in handbooks on children's hygiene written by Brazilian physicians. These books, whose target audience comprised the mothers and teachers who were in charge of educating these children, sought to explain the origin of the most common behavioral problems and offered instructions on how to overcome these difficulties, which jeopardized the child's development and also its adjustment to family and school. A preliminary analysis of two manuals approached from the perspective of the theoretical framework of Foucault and other authors on governmentality suggests that the books in question endeavored first and foremost to orient adults to make good use of power in their relations with children.}

Keywords: hygiene handbooks; child care; history of children and the family; problem child; governmentality. 
$\mathrm{A}$ partir da pesquisa sobre as orientações para a educação da criança-problema em compêndios de higiene infantil redigidos por médicos brasileiros, busca-se responder às seguintes questões: Como os médicos procuravam explicar os problemas de comportamento nas crianças? Como se apropriavam das teorias psicológicas disponíveis para compreendê-los? Que tipo de orientações práticas para as famílias e as professoras esses doutores procuravam derivar das teorias e de sua experiência profissional?

Destinados às mães e professoras encarregadas da educação das crianças, os manuais de higiene infantil procuravam explicar a origem de problemas de comportamento tais como a mentira, o furto, a teimosia, o medo, a agressividade, a timidez etc. Em seguida, ofereciam instruções para a superação dessas manifestações que, segundo os especialistas, prejudicavam o desenvolvimento infantil e o ajustamento da criança à família e à escola. A análise das obras indicadas baseia-se no texto "A governamentalidade", de Michel Foucault (1996), e no livro Governing the present: administering economic, social and personal life, de Peter Miller e Nikolas Rose (2008).

Foucault (1996) examina a literatura produzida entre os séculos XVI e XVIII na Europa sobre a arte de governar. Trata-se de um conjunto numeroso de textos que se opõem à perspectiva de governo presente na obra O Príncipe, de Maquiavel. Nesse famoso tratado, o governo é entendido como a habilidade do governante em conservar o seu principado, que é concebido como algo que lhe pertence, mas cuja posse está constantemente ameaçada por perigos externos e internos. Sendo assim, o governo é algo singular, que diz respeito exclusivamente à relação entre o príncipe e seu principado. Contudo, de acordo com os textos que se contrapõem a essa concepção, "Ser hábil em conservar seu principado não é de modo algum possuir a arte de governar" (Foucault, 1996, p.280). A arte de governo é conceituada como algo mais geral, que se exerce em vários níveis e em diversas situações: o professor governa os seus alunos, o patrão governa os seus empregados, o pai de família governa os seus filhos e assim por diante. Sendo assim, o governo do Estado é apenas uma entre muitas outras modalidades de governo.

Um dos primeiros livros representativos dessa literatura que se opõe a Maquiavel intitulase Miroir politique contenant diverses manières de gouverner (1567), da autoria de Guillaume de La Perrière. Nessa obra afirma-se que "governo é uma correta disposição das coisas de que se assume o encargo para conduzi-las a um fim conveniente" (citado em Foucault, 1996, p.282). De acordo com essa perspectiva, o cerne do governo deixa de ser o controle sobre o território e os súditos e passa a ser alcançar diversos objetivos distintos, empregando-se para isso táticas variadas, pensadas em função de cada um dos objetivos que se pretende alcançar, como, por exemplo: levar os alunos a aprender; fazer com que as crianças se comportem; fazer com que os empregados trabalhem e assim por diante. Para que as estratégias de governo possam ser bem formuladas, é preciso que se fundamentem em saberes sobre os governados: suas capacidades, seus limites, suas necessidades. Baseando-se nesses conhecimentos, os governantes podem desenvolver táticas mais eficazes e atingir melhores resultados ao conduzir a conduta dos governados em direção aos objetivos estabelecidos.

Conforme Foucault (1996), foi a partir do século XVIII que a arte do governo alcançou um desenvolvimento mais expressivo, e o fator decisivo para que isso ocorresse foi a descoberta da população como alvo específico do governo do Estado, em substituição à família, que havia 
sido até então a unidade básica do governo na Europa ocidental. Uma vez que o governo do Estado tomou a população como seu objeto privilegiado, seus problemas prioritários passaram a ser uma série de fenômenos medidos pelas estatísticas: as taxas de natalidade e mortalidade; os movimentos migratórios; a expectativa de vida e os fatores que interferiam nesses índices. A partir do momento em que uma população bem constituída tornou-se um recurso valioso para o Estado, os objetivos do governo passaram a ser a defesa da vida e do bem-estar da população. A modalidade de poder exercido sobre as dinâmicas populacionais, Foucault denominou biopolítica. Enquanto na Idade Média o poder soberano funcionava de acordo com uma lógica dedutiva, cujo objetivo era arrancar dos súditos tudo que eles pudessem oferecer - trabalho, impostos, a própria vida -, a arte do governo funcionava segundo uma lógica produtiva, interessada em ampliar o potencial da população, em termos de saúde, riqueza e até mesmo felicidade, em vez que tudo isso passara a ser visto como formas de fortalecer o Estado.

Pois qual pode ser o objetivo do governo? Não certamente governar, mas melhorar a sorte da população, aumentar sua riqueza, sua duração de vida, sua saúde etc. E quais são os instrumentos que o governo utilizará para alcançar estes fins, que em certo sentido são imanentes à população? Campanhas, através das quais se age diretamente sobre a população, e técnicas que vão agir indiretamente sobre ela e que permitirão aumentar, sem que as pessoas se deem conta, a taxa de natalidade ou dirigir para uma determinada região ou para uma determinada atividade os fluxos de população etc. (Foucault, 2004, p.289).

No texto de introdução ao livro Governing the present (2008), Peter Miller e Nikolas Rose, tendo em vista a produção acadêmica que se seguiu ao trabalho de Foucault, propõem que a governamentalidade seja considerada não apenas um conceito, mas um campo de pesquisas, um modo específico de estudar questões relacionadas à transformação da conduta, à 'ação sobre a ação' de outros ou de si mesmo (autogoverno), com vistas a atingir determinados objetivos. Para esses autores, em primeiro lugar, as pesquisas no campo da governamentalidade devem identificar um aspecto da existência que, em determinado momento e em condições específicas, se tornou um problema a ser investigado e enfrentado por especialistas e autoridades. Trata-se de compreender o modo como determinado tipo de ação, conduta ou comportamento passa a ser, em um contexto específico, visto como problemático e passível de intervenção ou correção (Miller, Rose, 2008, p.15). Em segundo lugar, os estudos sobre a governamentalidade devem levar em conta dois aspectos da arte de governar, os quais se encontram em estreita relação: racionalidades e tecnologias, ou seja, de um lado, modos de formular e compreender as questões de governo, de outro lado, modos de intervir na realidade com o objetivo de solucionar os problemas identificados. Essa perspectiva é útil para a análise de como os pediatras discorriam sobre o que identificavam como desvios de comportamento nas crianças e dos modos como entendiam ser necessário intervir nas dinâmicas familiar e escolar para prevenir o aparecimento desses problemas ou corrigi-los, nos casos em que já se houvessem instalado.

O desenvolvimento da pediatria e da puericultura no Brasil ocorreu a partir das últimas décadas do século XIX e está ligado à progressiva valorização social da infância como período em que se forjava o cidadão do futuro. O investimento público na saúde e na educação das 
crianças tornou-se estratégico para o fortalecimento da nação e provocou mudanças nos modos tradicionais de conduzir a gestação, o parto e a criação dos filhos (Rodríguez Ocaña, Perdiguero, 2006). A maternidade revestiu-se de importância política e tornou-se um 'dever nacional' a ser cumprido conforme as recomendações científicas formuladas pelos médicos puericultores (Freire, 2008, 2009).

Data de 1882 a criação do primeiro "curso de clínica das moléstias das crianças" no Serviço da Policlínica Geral do Rio de Janeiro, iniciativa levada a efeito por Carlos Arthur Moncorvo de Figueiredo (Telles, 1996). Antes mesmo da institucionalização dessa especialidade médica, foram publicados em nosso país os primeiros manuais de puericultura, compêndios nos quais os médicos procuravam orientar as mães sobre como cuidar adequadamente de seus filhos na primeira infância. De acordo com Martinho da Rocha (1996, p.164), o volume inaugural tem como título A guia médica das mães de família, e foi escrito por Jean-Baptiste Alban Imbert em 1843. Nas primeiras décadas do século XX, esse tipo de literatura alcançou uma grande divulgação e, ao lado das revistas femininas e dos cursos de puericultura nas escolas normais, se tornou parte importante da educação da mulher-mãe moderna (Freire, 2008).

Por meio da escrita dos manuais de puericultura os médicos pretendiam atuar como educadores das mães e professoras, tornando-as suas aliadas no combate à mortalidade infantil, um dos mais graves problemas de saúde pública com que se defrontava a medicina da época. Entendiam que era preciso agir preventivamente, esclarecendo as mulheres sobre todos os cuidados necessários para criar uma criança saudável e bem-educada. Combatiam saberes e costumes populares associados à ignorância, crendices e superstições que punham em risco a saúde dos bebês e de suas mães e propunham a sua substituição por práticas orientadas pela higiene infantil (Martins, 2008).

À medida que conquistavam a confiança das mães e das famílias, os pediatras passaram a se interessar cada vez mais por questões relacionadas não apenas aos problemas de saúde física, mas também pelo desenvolvimento físico e mental e os transtornos de comportamento na infância. Logo os compêndios de puericultura passaram a dedicar cada vez mais espaço à higiene mental. A leitura desses textos sugere que o pediatra, à medida que ganhava credibilidade como especialista, foi sendo investido de autoridade para ensinar aos pais e educadores como deveriam exercer o poder sobre seus filhos e alunos, tendo em vista formar cidadãos bem ajustados à sociedade. A seguir, apresenta-se um estudo exploratório de dois livros escritos por médicos brasileiros interessados em contribuir para a prevenção e a correção dos problemas de comportamento nas crianças, por meio do esclarecimento das mães e professoras.

\section{O saber médico e o governo das crianças em casa e na escola}

Em 1947 foi publicado o livro Prepara teu filho para a vida: educação psicológica da criança, do doutor Odilon de Andrade Filho. Por entender que já havia muitos guias de qualidade dedicados a divulgar os princípios de higiene física da criança, nesse manual o autor decide dedicar-se exclusivamente ao tema da higiene mental.

$\mathrm{O}$ alvo privilegiado das orientações nesse caso era a família, pois o autor entendia que era no lar que se formavam as bases físicas e psíquicas da individualidade, que a escola iria 
desenvolver posteriormente. O livro trata de diversos problemas de comportamento, tais como: inapetência, insônia, ciúme, cólera, medo, teimosia, timidez etc. Também dedica alguns capítulos especificamente às relações entre adultos e crianças: "Autoridade e disciplina"; "Educação e castigos"; e ainda "Por que são as mães carinhosas em demasia?"; "Consequências do excesso de carinhos". Esses títulos indicam que os médicos pretendiam não apenas ensinar os pais a fazer um bom uso do poder, mas também orientá-los a ajustar a economia afetiva do lar, evitando o excesso de manifestações amorosas.

Preocupação semelhante aparece em outro compêndio publicado na mesma época. Trata-se de A criança-problema: higiene mental na escola primária, redigido em 1939 por Arthur Ramos, médico formado pela Faculdade de Medicina da Bahia. O livro apresenta casos de crianças acompanhadas por Ramos e sua equipe no Serviço de Higiene Mental da Seção de Ortofrenia e Higiene Mental do Instituto de Pesquisas Educacionais, instalada em 1934 no então Distrito Federal (Patto, 1990, p.80). Na introdução de seu trabalho, Ramos explica que a expressão no título do livro havia sido criada com o objetivo de adequar a designação das crianças que, sem serem anormais, haviam tornado-se desajustadas devido às condições precárias do ambiente em que viviam.

O objetivo de Ramos era demonstrar que grande parte dos alunos das escolas primárias considerados crianças anormais por suas professoras era apenas vítima de meios familiares inadequados. Sendo assim, a verdadeira causa da maior parte dos desajustamentos era devida a erros educativos dos pais e não a doenças mentais das crianças. Tanto quanto Andrade Filho, Ramos acreditava que era possível prevenir a maioria dos problemas de comportamento das crianças instruindo os adultos a fazer um bom uso do poder e a moderar as manifestações de afeto no interior da família. Nesse livro, a primeira parte é dedicada ao estudo das causas dos desajustamentos infantis e trata de temas como: "A criança mimada"; "A criança escorraçada"; "As constelações familiares"; "O filho único"; e "Avós e outros parentes". Na segunda parte, descrevem-se os problemas de comportamento observados pelo autor nas crianças que frequentavam as escolas públicas do Distrito Federal na década de 1930 e que eram encaminhadas ao serviço dirigido por ele. Cada capítulo era dedicado a um tipo de distúrbio: "A criança turbulenta"; "Tiques e ritmias"; "As fugas escolares"; "Os problemas sexuais"; "Medo e angústia" e assim por diante.

Recorrendo-se ao conceito de governamentalidade, tal como formulado por Foucault (1996), pode-se afirmar que o tema principal desses livros era o governo das crianças, entendendo-se o governo como a "conduta da conduta" de alguém tendo em vista um objetivo específico que, nesse caso, era o ajustamento social dos governados. Procurava-se, em ambos os casos, ensinar as mães e as professoras a 'conduzir a conduta' das crianças em casa e na escola até que essas se tornassem capazes de exercer o autogoverno. Pode-se ainda constatar que, à medida que orientavam a conduta dos adultos em relação ao uso da autoridade e à administração dos afetos, os médicos pretendiam, em primeiro lugar, governar as famílias e os educadores. Portanto, governo em dois níveis, ou em dois tempos: dos doutores em relação aos leitores dos compêndios e desses leitores em relação às crianças. O problema que os médicos procuravam enfrentar era o do desajustamento da criança ao meio social, e a intervenção que entendiam ser necessária para superá-lo era a orientação dos pais.

Em que se baseavam e qual o conteúdo das orientações proferidas pelos doutores? 
A leitura dos compêndios indica que os seus autores estavam atualizados acerca dos conhecimentos especializados na área da educação, da psicologia e da psicanálise produzidos em sua época. Arthur Ramos teve uma atuação decisiva na divulgação das ideias psicanalíticas no meio educacional e, à luz dessa teoria, participou intensamente do movimento da higiene mental infantil, inclusive da direção do serviço em que foram atendidos os casos relatados em A criança-problema (1939). Além desse livro, escreveu Educação e psicanálise (1934), e Freud, Adler, Jung: ensaios de psicanálise ortodoxa e herética (s.d.). Procurando compreender os desajustamentos infantis a partir de uma perspectiva psicanalítica, era avesso aos diagnósticos produzidos exclusivamente por meio da aplicação de testes psicológicos, os quais, a seu ver, eram incapazes de dar conta da complexidade da maioria dos problemas infantis. No Serviço de Ortofrenia e Higiene Mental comandado pelo autor, recorria-se a avaliações mais extensas, que combinavam procedimentos heterogêneos, incluindo a coleta de informações sobre as condições vividas pela criança no seu ambiente familiar e exames médico-orgânicos e neuropsicológicos, além dos testes psicológicos, de modo que se pudesse traçar um perfil mais completo da criança (Ramos, 1939, p.23-24).

A análise da obra de Ramos indica que a psicanálise era um recurso teórico útil para pensar sobre o processo de ajustamento do indivíduo à vida social. Assim como boa parte dos especialistas que tomaram conhecimento da obra de Freud na primeira metade do século XX, Ramos esperava que o conceito freudiano de sublimação produzisse efeitos transformadores nos estudos da área da orientação profissional, posto em que permitia vislumbrar a possibilidade de derivar as inclinações instintivas da criança para trabalhos socialmente valorizados (Ramos, 1934, p.157).

Quanto a Odilon de Andrade Filho, o compêndio Prepara teu filho para a vida menciona em sua extensa bibliografia diversos expoentes da literatura pedagógica e psicológica nacional e internacional de sua época. Entre os brasileiros, Andrade cita Fernando Azevedo, Helena Antipoff, Franco da Rocha, além de Arthur Ramos. Entre os estrangeiros, destacam-se Arnold Gesell, com vários títulos, além de Alfred Adler, Alfred Binet, Edouard Claparède, Sigmund Freud e Ana Freud, Jean Piaget e Stanley Hall. A diversidade de referências e as orientações formuladas atestam que o autor não hesitava em recorrer a perspectivas teóricas distintas com o objetivo de compreender e solucionar os problemas de comportamento apresentados pelas crianças. Pode-se afirmar que tanto Arthur Ramos como Odilon de Andrade Filho fundamentavam seus conselhos para pais e professores não apenas em sua experiência profissional, mas também na vasta literatura médica, pedagógica e psicológica disponível no país e no exterior nas primeiras décadas do século XX.

Quanto ao conteúdo das orientações, entendiam que, desde que se compreendesse a criança, seria fácil orientá-la. Andrade Filho descrevia as características tipicamente infantis, tais como a impetuosidade, o egoísmo, a dispersão, a teimosia, mas também a tendência à imitação e à flexibilidade, para depois mostrar ao leitor como conduzir a educação das crianças de maneira inteligente e produtiva. Considerava que era preferível deixar passar muita coisa em vez de corrigir uma criança a cada momento. Por outro lado, quando fosse preciso negar a satisfação de um desejo, era preciso ser firme e não voltar atrás diante das manifestações de contrariedade da criança. 
Embora fosse avesso aos castigos físicos, Andrade Filho admitia o emprego do "condicionamento por meios físicos", que consistia no "processo pelo qual se procura associar à prática de um ato condenável uma correção, sempre a mesma, como um tapa na mão" (1947, p.202). Arthur Ramos, por sua vez, manifestava-se enfaticamente contra os castigos físicos e entendia que essa prática, ainda muito disseminada nas escolas rurais de seu tempo, muitas vezes explicava o desajustamento da criança. $\mathrm{O}$ autor observava que frequentemente o aluno turbulento era agredido em casa pelos pais e tendia a manifestar no espaço mais livre da instituição escolar a sua revolta contra a violência sofrida no espaço doméstico.

\section{Administrar os afetos para prevenir os desajustamentos na infância}

Tanto para Odilon de Andrade Filho como para Arthur Ramos, a justa medida entre o excesso e a falta precisava ser buscada não apenas em relação ao exercício da autoridade e à exigência de disciplina, mas também nas manifestações afetivas. Os dois autores entendiam que as atenções dispensadas às crianças pelos avós, madrinhas, tias solteironas e amas costumavam produzir crianças mimadas, tanto que Ramos dedicava um título de seu compêndio ao tema "avós e outros parentes" na parte referente às causas dos desajustamentos. De maneira análoga, Andrade Filho apresentava em seu guia um capítulo intitulado "Educação pelos avós", em que afirmava: "São os avós, frequentemente, perigosos elementos para a formação psíquica das crianças" (1947, p.213). Apesar de sua indiscutível boa vontade, os avós quase sempre prejudicavam a educação da criança, pois tendiam a satisfazer todos os seus desejos. Sendo assim, evidenciava-se a preocupação dos autores inclusive com as crianças muito bonitas, inteligentes, ricas ou amadas. Havia, portanto, uma justa medida das atenções, dos agrados e dos elogios, a qual deveria ser observada, sob pena de se estragarem as novas gerações.

Em Odilon de Andrade Filho chama atenção a recorrência da recomendação de se proporcionar às crianças a oportunidade de conviver com colegas da mesma idade. Para esse autor, essa medida poderia ajudar a resolver os problemas mais variados, desde os maus hábitos de chupar o dedo ou roer unhas até a superação dos medos infantis, a inapetência e os ataques de cólera. Assim como seus colegas de profissão, Andrade Filho era favorável às brincadeiras e aos exercícios físicos praticados ao ar livre como medida profilática para a saúde física e mental. Por outro lado, alertava para o perigo das leituras, das revistas em quadrinhos, do cinema e tudo o mais que pudesse impressionar a sugestionável imaginação das crianças. Os doutores pareciam confiar mais na natureza e na própria infância como recursos educativos do que na cultura produzida pelos adultos civilizados de seu tempo. Seus textos indicam que, à maneira de Rousseau, os pediatras no fundo desconfiavam que os pais pudessem ser bons educadores e acreditavam que moderar sua convivência com eles era bom para o desenvolvimento infantil. Se defendiam a entrada da criança na escola, era principalmente para afastá-la da convivência demasiado estreita com a mãe e outros parentes e para propiciar-lhes, alternativamente, o contato com crianças da mesma idade em um espaço ampliado, de liberdade vigiada. 


\section{Considerações finais}

No atual estágio de desenvolvimento da pesquisa, as questões formuladas no início deste texto apenas começam a ser exploradas. A leitura dos dois manuais mencionados indica que os problemas de comportamento que ocupavam os autores eram os de adaptação da criança à família e à escola, os quais, segundo eles, permitiam antever dificuldades futuras de ajustamento social. Em um período em que os investimentos na saúde e na educação das crianças eram vistos como estratégicos para formar uma população vigorosa, pronta para trabalhar pelo desenvolvimento da pátria, evitar os problemas de conduta desde a infância não era apenas uma preocupação das famílias e das escolas, mas um objetivo político ligado aos destinos da nação.

Informados pelas teorias psicológicas de seu tempo, em particular pela psicanálise, os autores entendiam que as relações familiares tinham um papel decisivo na formação da personalidade. Por um lado, acreditavam ser possível prevenir grande parte dos desvios de conduta apresentados pelas crianças por meio da orientação psicológica dos pais. Por outro lado, tendo em vista a intensidade dos afetos que caracterizavam as relações familiares, em especial aquelas que se estabeleciam entre a criança e a mãe, pareciam desconfiar da possibilidade de promover a adequada regulação dessas relações. Para evitar uma convivência demasiado estreita com a mãe, sugeriam que a criança deveria ir logo para a escola, que parecia ser uma instituição mais adequada para promover o ajustamento social. No entanto, na percepção dos autores, dificilmente a escola seria capaz de sobrepor sua influência à da família, daí a necessidade de se investir simultaneamente no esclarecimento dos pais em matéria de desenvolvimento infantil. Era preciso compreender a criança para bem orientála, mas essa compreensão não estava acessível ao observador comum. O olhar da mãe e da professora dirigido ao filho ou ao aluno precisava ser cientificamente preparado. Para bem educar a criança, não se devia reagir às suas manifestações intuitivamente, mas de maneira refletida, fundamentada nos conhecimentos científicos disponíveis sobre o que se tinha como 'natureza' infantil e vislumbrando-se as qualidades desejadas para o seu futuro, de cidadão da pátria.

\section{REFERÊNCIAS}

ANDRADE FILHO, Odilon de.

Prepara teu filho para a vida: educação psicológica da criança. Rio de Janeiro: José Olympio. 1947.

FOUCAULT, Michel.

A governamentalidade. In: Foucault, Michel. Microfísica do poder. Rio de Janeiro: Graal. p.277-293. 1996.

FREIRE, Maria Martha de Luna. Mulheres, mães e médicos: discurso maternalista no Brasil. Rio de Janeiro: Editora FGV. 2009.

FREIRE, Maria Martha de Luna.

'Ser mãe é uma ciência': mulheres, médicos e a construção da maternidade científica na década de 1920. História, Ciências, Saúde-Manguinhos, Rio de Janeiro, v.15, supl., p.153-171. 2008.
MARTINS, Ana Paula Vosne.

"Vamos criar seu filho": os médicos puericultores e a pedagogia materna no século XX. História, Ciências, Saúde - Manguinhos, Rio de Janeiro, v.15, n.1, p.135-154. 2008.

MILLER, Peter; ROSE, Nikolas.

Governing the present: administering economic, social and personal life. Cambridge: Polity Press. 2008.

PATTO, Maria Helena Souza.

A produção do fracasso escolar: histórias de submissão e rebeldia. São Paulo: T.A. Queiroz. 1990.

RAMOS, Arthur.

A criança problema: a higiene mental na escola 
primária. São Paulo, Rio de Janeiro, Recife, Porto Alegre: Companhia Editora Nacional. 1939.

RAMOS, Arthur.

Educação e psicanálise. São Paulo: Companhia Editora Nacional. 1934.

RAMOS, Arthur.

Freud, Adler, Jung: ensaios de psicanálise ortodoxa e herética. Rio de Janeiro: Editora Guanabara. s.d.

ROCHA, José Martinho da.

Pequena crônica da puericultura e pediatria brasileiras. In: Aguiar, Álvaro; Martins, Reinaldo M. (Ed.). História da pediatria brasileira: coletânea de textos e depoimentos. Rio de Janeiro: Nestlé. p.163-169. 1996.
RODRÍGUEZ OCAÑA, Esteban; PERDIGUERO, Enrique.

Ciencia y persuasión social en la medicalización de la infância em España, siglos XIX-XX. História, Ciências, Saúde - Manguinhos, Rio de Janeiro, v.13, n.2, p.303-324. 2006.

TELLES, Walter.

Um século de pediatria. In: Aguiar, Álvaro; Martins, Reinaldo M. (Ed.). História da pediatria brasileira: coletânea de textos e depoimentos. Rio de Janeiro: Nestlé. p.147-152. 1996. 